\title{
Peer Influence on Young Adults' Products Purchase Decisions
}

\begin{abstract}
Hasan Ashraf Khan, Yasir Kamal', Shehroz Saleem²
Abstract

This study investigates the influence of peers on young adults' product purchase decisions in Pakistan where the values and cultures differ because of significant religious influence and geographic dispersion. Data is collected from a convenience-based sample of university students via two questionnaires. Using different analysis techniques such as comparisons of means, analysis of variance, and LSD, results support the construct that peers do influence young adults' product purchase decisions. A number of variables and variations in the level of education, exposure, affluence or other cultural and societal differences etc. impose limitations on the study which can be removed through future studies. The research suggests marketers to pay special attention and invest in creative options for utilizing peer groups for sales and promotion of their products and brands.
\end{abstract}

Keywords: Peer influence, purchase decisions, adults, analysis of variance.

\section{Introduction}

There are a number of factors which influence or affect choices and important decisions in life. For a marketer, it is important to be aware of influences that affect purchasing decisions so that the same can be utilized effectively while pursuing the marketing endeavours for any firm. Although the demographic, social, cultural, psychographic, and personal factors all form a complex recipe, but since these factors are received by an individual through societal influences, the individuals interacting with each other form a major source of transmission of such influences. People that comprise such concentric circles of influences are known as "reference groups", synonymous to the societal function they perform, i.e. provision of a source of reference for the various responses an individual produces when confronted with various options.

All promotional efforts are debated amongst people and are either approved or disapproved. Therefore, it is natural for a marketer to be interested in the word of mouth from reference groups. Word of mouth has become the buzz word of marketing circles in the western hemisphere.

Evolutionary changes affecting the Pakistani society are also bringing about shift

1 Corresponding Author. Assistant professor, Institute of Management Sciences, Peshawar. Email: yasir.kamal@imsciences.edu.pk

2 PhD Scholar, Institute of Management Sciences, Peshawar. Email: shehroz20@gmail.com 
in the importance of various reference groups in decision making situations.

The purpose of the current study, which is a partial replication of the study by Makgosa and Mohube (2007), is to investigate the influence of peers on young adults' product purchase decisions in Pakistan.

\section{Literature Review}

Bristol and Mangleburg (2005) define peer influence as the extent to which peers exert influence on the attitudes, thoughts, and actions of an individual. According to Escalas and Bettman (2005), reference groups can be a critical source of brand meanings. Consumers use other people-particularly those who share similar beliefs and dimensions-as a source of information for arriving at and evaluating one's beliefs about the world. Kotler and Armstrong (2008) define the word of mouth influence as a personal source of communication about a product between the target buyers and other societal groups like neighbours, friends, family members, and associates.

Godes and Mayzlin (2004) and Maxham and Netemeyer (2002) studied word-ofmouth (WOM) that has been perceived as a standout amongst the most compelling sources of data transmission from the start of human culture. Laroche, Papadopoulos, Heslop, and Mourali (2005) portrayed the significant change in data transmission with the rise of online social websites. Institutions, individuals or groups conceived of having significant relevance upon an individual's evaluations, aspirations, or behaviour (Park \& Lessig, 1975; Pentina, Prybutok, \& Zhang, 2008).

Childers and Rao (1992) identified two types of reference groups that influence the purchase decisions, 1) normative referents (e.g. parents, teachers, and peers) which provide an individual with norms, attitudes, values, etc., and 2) comparative referents (e.g. sports heroes and entertainment figures) which provide standards of achievement. Bearden and Etzel (1989) found consumer susceptibility to interpersonal influence and described it as the need to identify or enhance one's image. Yoh (2005) revealed that peers were the most frequently mentioned information source for college students' athletic shoe purchases, which was found to be consistent with previous studies.

Bush, Bush, Clark and Bush (2005) found WOM being used as a marketing technique dubbed as "Buzz Marketing". They referred to several previous researches (see for example, Mangold, 1999; Murray, 1991; Richins, 1983) implying that WOM can create a strong impact on consumers' purchase behavior and satisfaction associated to the products and services they acquire. They found consumers' tendency to rely more on and even prefer personal information sources for services than for products. Tischler (2004) found agencies created solely to help clients create buzz. One of these 
agencies is a Boston company Buzz Agent that has assembled a nationwide army of volunteers who can promote any of the clients' products they deem worth promoting. Procter \& Gamble have started two of their own WOM networks; Tremor, for teens, and Vocal Point, for mothers (Gelles, 2005).

Duan, Gu, and Whinston (2008) recognized the importance of person-to-person WOM. They also supported the idea that the use of internet for publicizing feedback and recommendations on products and businesses have broadened the reach of WOM (Chen \& Xie, 2004; Dellarocas, 2003. Their findings support the idea that online WOM process has a significant impact on sales (Katz \& Lazarsfeld, 1955; Foster \& Rosenzweig, 1995).

Fong and Burton (2006) support the importance electronic discussion boards have gained as an additional channel for product recommendations and endorsements between people who have never met and find those recommendations to be influential. Brown and Reingen (1987) find prevalent WOM communication influences particularly when considering the purchase of a new product or service.

Kotler and Keller (2006) cautioned companies to be careful about negative WOM. Taylor (2003) found Web sites like troublebenz.com and lemonmb.com, created to provide discussion forum for dissatisfied Mercedes owners. For a positive WOM, they referred to Zagat's Website which provides rating for restaurants, hotels, resorts, spas, and other services by recruited reviewers in their respective localities. Websites and blogs provide effective platforms where shoppers can send e-mails, complaints, compliments, suggestions, or questions directly to a company with the option to post comments publicly (Spencer, 2003). They describe services as generally high in experience and credence qualities having more risk in purchase; therefore, service consumers generally rely on word of mouth rather than advertisement. They conclude by quoting Pete Blackshaw, the Chief Marketing Officer of Intelliseek, who describes the Internet as a word of mouth on steroids. According to him, a satisfied customer tells only three people about a good product experience while an average dissatisfied customer gripes to 11 people.

Kotler and Keller (2006) describe personal influence to carry great weight when the products are expensive, risky, or purchased infrequently and where the product suggests something about the user's status or taste. Service providers have been found to have a strong interest in building referral sources. Trusov, Bucklin, and Pauwels (2006) estimated that WOM is around 20 times higher than the versatility of promotional programs $(0.53$ versus 0.026$)$ and 30 times higher than the versatility of media appearances $(0.53$ versus 0.017$)$. East (2005), in an audit of 23 administration classes, found that WOM had more prominent reporting effect on brand decision 
than publicizing or individual pursuit. Minsner (1999) calls word-of-mouth the world's best, yet minimum comprehended promoting technique. Katz and Lazarsfeld (1955) observed WOM to be seven times more compelling than print media in impacting shoppers to switch brands.

Mak's (2008) findings support that opinion pioneers are mostly frequent purchasers with direct impact constrained to just a couple of kindred buyers depicted as devotees or assessment seekers.

Borgida and Nisbett (1977) and Herr, Kardis, and Kim (1991) shown that face to face WOM greatly affects shoppers' decisions due to its clarity and validity. Duan et al. (2008) findings are consistent with Godes and Mayzlin (2004) that online WOM is not only a precursor to, but also an outcome of, product sales. Currie and Wesley (2006) support past analysts by exhibiting a solid impact of associate reference bunches on services buying choices, particularly tourism destination decisions.

\section{Methodology}

\subsection{Sample}

A simple random sample comprising of fifteen students out of 583 in total (both males and females) of Shaheed Zulfiqar Ali Bhutto Institute of Sciences and Technology (SZABIST) University comprised the first survey. Due to paucity of time, the next survey also comprised of random sample of one hundred and one students (both male and female) from different departments and different stages of their study programs at SZABIST. As a pilot survey, the study conducted interviews from 15 different students to identify the items for developing the questionnaire.

\subsection{Questionnaire}

The study uses two questionnaires for data collection. The first questionnaire comprised of basic individual information and a question regarding rank ordering of the 15 short listed items (from the interviews conducted earlier). The second questionnaire was used to collect data regarding the degree of influence the subjects experience from their family (parents and siblings), peers (friends, colleagues and classmates), advertising and media, different information technology sources, and any celebrity the subjects idealize. All questions comprised of a 5-point Likert scale.

\subsection{Procedure}

Using the interview results of faculty and students of SZABIST, a list of 15 items was developed where items were considered to be high in relevance and purchase 
probability for young adults. The first survey comprised of these short listed 15 items. Students were given a brief explanation about the survey and were asked to rank order the 15 items to obtain 5 such items that draw maximum amount of influence from various quarters while making a purchase decision.

The second survey was conducted through another questionnaire given to a different student sample of the same institute. In this, questions regarding the 5 items (obtained after the first survey) were asked to choose the degree of influence which various sources exerted on them while purchasing products.

\section{Results and Analysis}

The results of the first survey concerning rank ordering of the fifteen items are presented in Table 1.

Table I: Mean Scores Comparison - Top Items

\begin{tabular}{|c|c|c|c|c|}
\hline $\begin{array}{c}\text { S. } \\
\text { No. }\end{array}$ & Item & Mean & $\begin{array}{c}\text { Standard } \\
\text { Deviation }\end{array}$ & $\begin{array}{c}\text { Order of Merit on } \\
\text { the basis of mean }\end{array}$ \\
\hline 1 & Mobile & 5.3125 & 4.5712 & 03 \\
\hline 2 & Garments (Jeans or any Dress) & 5.5625 & 3.2857 & 04 \\
\hline 3 & Shoes (Snickers) & 7.7500 & 3.0441 & 07 \\
\hline 4 & Wallet or Purse & 11.0630 & 3.0869 & 14 \\
\hline 5 & Tooth Paste & 10.6250 & 4.0968 & 12 \\
\hline 6 & Perfume & 6.7500 & 3.4351 & 05 \\
\hline 7 & Computer/Laptop & 4.1250 & 3.1172 & 02 \\
\hline 8 & Admission in Professional Colleges & 3.1875 & 3.6004 & 01 \\
\hline 9 & Cassettes or Music CDs & 10.0630 & 3.4731 & 11 \\
\hline 10 & Sound System & 8.6250 & 4.1613 & 08 \\
\hline 11 & Snacks (Fries or Fast Food etc.) & 9.1250 & 3.5567 & 10 \\
\hline 12 & Wrist Watch & 8.8125 & 3.1245 & 09 \\
\hline 13 & Calculator & 11.1880 & 2.7861 & 15 \\
\hline 14 & Mobile Service Provider & 7.0000 & 3.3267 & 06 \\
\hline 15 & Note Book/ Copy & 11.0000 & 4.7469 & 13 \\
\hline
\end{tabular}


Table 2: Top Influence Drawing Items

\begin{tabular}{|c|c|c|c|c|}
\hline $\begin{array}{c}\text { S. } \\
\text { No. }\end{array}$ & Item & Mean & $\begin{array}{c}\text { Standard } \\
\text { Deviation }\end{array}$ & Order of Merit \\
\hline 1 & Admission in Professional Colleges & 3.1875 & 3.6004 & 01 \\
\hline 2 & Computer/Laptop & 4.1250 & 3.1172 & 02 \\
\hline 3 & Mobile & 5.3125 & 4.5712 & 03 \\
\hline 4 & Garments (Jeans or any Dress) & 5.5625 & 3.2857 & 04 \\
\hline 5 & Perfume & 6.7500 & 3.4351 & 05 \\
\hline
\end{tabular}

As evident from Table I, it can be observed that the mean scores for items having the highest drawn influence is lower in comparison to other items in the list. The top influence drawing items which formulate the basis of the next survey are presented in Table 2.

After having these five items declared as the most influence drawing objects for the young adults, in the next survey a questionnaire was prepared to gauge the degree of influence these items drew from various sources forming the main circles of influence or reference groups for the young adults.

The results of the second questionnaire are presented in Table 3.

Table 3: Mean Scores for Influences from Various Sources on Separate Items

\begin{tabular}{|c|c|c|c|c|c|c|}
\hline & Over all & Family & Peers & Media & $\begin{array}{c}\text { IT Sourc- } \\
\text { es }\end{array}$ & $\begin{array}{c}\text { Person- } \\
\text { ality }\end{array}$ \\
\hline $\begin{array}{c}\text { Adm. in Prof. } \\
\text { Colleges }\end{array}$ & .3248 & .7822 & .4257 & -.0594 & .3267 & .1485 \\
\hline Standard Deviation & .63046 & 1.14546 & 1.11666 & 1.15604 & 1.27365 & 1.26796 \\
\hline Order of Influence & & 1 & 2 & 5 & 3 & 4 \\
\hline Computer \& Laptop & .6317 & .5149 & .7030 & .8515 & 1.0891 & .0000 \\
\hline Standard Deviation & .63858 & 1.17144 & .93322 & 1.02358 & .99095 & 1.31149 \\
\hline Order of Influence & & 4 & 3 & 2 & 1 & 5 \\
\hline Mobile Set & .5743 & .1188 & .7822 & .9703 & .7426 & .2574 \\
\hline Standard Deviation & .71255 & 1.29064 & 1.14546 & 1.10865 & 1.15459 & 1.27007 \\
\hline Order of Influence & & 5 & 2 & 1 & 3 & 4 \\
\hline Garments (Jeans etc.) & .4614 & .6040 & .6931 & .6337 & .2871 & .6634 \\
\hline Standard Deviation & .68687 & 1.19230 & 1.18104 & 1.22248 & 1.21109 & 1.26710 \\
\hline Order of Influence & & 4 & 1 & 3 & 5 & 2 \\
\hline
\end{tabular}




\begin{tabular}{|c|c|c|c|c|c|c|}
\hline Perfume & .2792 & .4158 & .4752 & .2871 & -.2871 & .5050 \\
\hline Standard Deviation & .80453 & 1.30589 & 1.18823 & 1.22749 & 1.04246 & 1.35369 \\
\hline Order of Influence & & 3 & 2 & 4 & 5 & 1 \\
\hline
\end{tabular}

Note: total $n=101$.

The mean scores reveal that the items having different nature draw major influences from separate sources, i.e. for "admission in professional colleges", family is found to be the major source of influence, for "purchase of computer and laptop", IT sources are the major influencers, for "purchase of a mobile set", media and advertising are found to be the major sources of influence, for "garments and jeans or dresses of daily wear", peers are found to be the major source of influence and for "purchase of perfumes", celebrities and personalities are the major sources of influence. It is important to note that the findings also validate common knowledge and cultural understanding.

Table 4 presents the average mean scores for influences drawn for making decisions for the five items from all the sources. Maximum mean value for the influence is for the peers (friends, colleagues and class mates) as they were consistently rated amongst the top three influencing sources for all the items, which is evident from Table 3 reported before.

Table 4: Mean Scores for Influences from Various Sources on all Items

\begin{tabular}{|c|c|c|c|c|c|}
\hline & Family $^{*}$ & Peers $^{*}$ & Media $^{*}$ & IT Sources $^{*}$ & Personality $^{*}$ \\
\hline Mean Scores for all items & .4871 & .6158 & .5366 & .3168 & .3149 \\
\hline Std. Dev. for all items & 1.23777 & 1.12111 & 1.20644 & 1.26091 & 1.31153 \\
\hline Order of Influence & 3 & 1 & 2 & 4 & 5 \\
\hline
\end{tabular}

Note: total $\mathrm{n}=101$. ${ }^{*}$ Cumulative for all items i.e. $101 \mathrm{X} 5$ or 505

Finally, a one-way analysis of variance (ANOVA) test was conducted for the collected data. Results of the test are presented in Table 5:

Table 5: Analysis of Variance

\begin{tabular}{|c|c|c|}
\hline Influence $^{*}$ & F. Ratio & Significance Level (P) $^{.003}$ \\
\hline Family (e.g. parents and siblings) & 4.090 & .098 \\
\hline Peers (e.g. friends, colleagues \& classmates) & 1.966 & .000 \\
\hline Media and advertising & 13.631 & .000 \\
\hline IT Sources i.e. Internet etc. & 29.318 & .002 \\
\hline Personality (Ideals and emulation) & 4.335 & \\
\hline
\end{tabular}


As evident from the results, Family, Media, IT Sources and Personality have significant p-values (at 5\% level of significance), showing that the means are not equal and vary across the samples. Only the variable "Peers" show an insignificant p-value which means that the null hypothesis for the equality of means can be accepted. This also shows that the influence reflected by the mean values calculated is consistent in all the samples, which is also supported by highest mean values as evident from Table 4. The consistent mean values across the samples support the hypothesis that peers do influence young adults' product purchase decisions.

\section{Conclusion}

The results of this study indicate that the influence of peers on young adults' product purchase decisions is an important factor even in Pakistan despite the existing differences in culture, values and effects of strong religious aspects and geographical dispersion from other regions where this factor is identified as a significant marketing construct in previous studies. It is also concluded that peer influence has a consistent impact across various domains where young adults make choices and decisions; although it may not be the strongest influence in that particular domain, yet it is significant.

There exists a lot of potential for further study in this area but it also requires efforts and funds to cater other variables that may have direct or indirect impact on young adults' product purchase decisions. Notwithstanding the limitations, it is now established that contemporary marketers cannot afford the luxury of disregarding this important construct, i.e. peers' influence on product purchase decisions. Giant firms like Proctor \& Gamble have taken a head start and formed youth groups like "Tremors" to exert peer influence, tilting youth purchase decisions in their favour. There exists a lot of untapped potential to use the influence of peers in the Pakistani market. All what is required is to harness this aspect in some creative fashion for utilizing peer groups for sales and promotion of local products and brands.

\section{References}

Bearden, W., \& Etzel, M. (1982). Reference group influence on product and brand purchase decisions. Journal of Consumer Research, 9(2), 183-194.

Borgida, E., \& Nisbett, R (1977). The differential impact of abstract vs. concrete information on decisions. Journal of Applied Social Psychology, 7(3), 258-271.

Bristol T., \& Mangleburg, T. F. (2005). Not telling the whole story: Teen deception in purchasing. Journal of the Academy of Marketing Science, 33(1), 79-95.

Brown, J. J, \& Reingen, P. H. (1987). Social ties and word-of-mouth referral behavior. Journal of Consumer 
Research. 14(3), 350-362.

Bush, V. D., Bush, A. J., Clark, P., \& Bush, R. P. (2005). Girl power and word-of-mouth behaviour in the flourishing sports market. Journal of Consumer Marketing, 22(5), 257-264.

Chen, Y., \& Xei, J. (2004). Word-of-mouth as a new element of marketing communication mix. Management Science, 54(3), 477-491.

Childers, T., \& Rao, A. (1992). The influence of familial and peer-based reference groups on consumer decisions. Journal of Consumer Research, 19(2), 198-211.

Currie, R. R., \& Wesley, F. (2008). Going where the Joneses go: Understanding how others influence travel decision-making. International Journal of Culture Tourism and Hospitality Research, 2(1), 12-24.

Dellarocas, C. (2003). The digitization of word-of-mouth: promise and challenges of online reputation systems. Management Science 49(10), 1407-1424.

Duan, W., Gu, B., \& Whinston, A. B. (2008). The dynamics of online word-of-mouth and product sales. An empirical investigation of the movie industry. Journal of Retailing, 84(2), 233-242.

Escalas, J., \& Bettman, J. (2005). Self-construal, reference groups, and brand meaning. Journal of Consumer Research, 32(3), 378-389.

Fong, J., \& Burton, S. (2006). Electronic word-of-mouth: A comparison of stated and related behavior on electronic discussion boards. Journal of Interactive Advertising, 6(2), 7-62.

Foster, D., \& Rosenzweig, M. 1995. Learning by doing and learning from others: Human capital and technical change in agriculture. Journal of Political Economy, 103(6), 1176-1209.

Gelles, J. (2005, December 04). Tremor: Shaky stuff. The Seattle Time. Retrieved from http://www. seattletimes.com/life/tremor-shaky-stuff/

Godes, D., \& Mayzlin, D. (2009). Firm created word-of-mouth communication: Evidence from a field test. Marketing Science, 28(4), 721-739.

Herr, P., Kardes, F., \& Kim, J. (1991). Effects of word-of-mouth and product-attribute information on persuasion: An accessibility-diagnosticity perspective. Journal of Consumer Research, 17(4), 454- 462.

Katz, E. \& Lazarsfeld, P.F. (1955). Personal influence: The part played by people in the flow of mass communications. The Free Press, New York

Kotler, P., \& Armstrong, G. (2008). Principles of marketing (12 ${ }^{\text {th }}$ ed.). New Delhi: Dorling Kindersley

Kotler, P., \& Keller, L. (2006). Marketing management ( ( $^{\text {th }}$ ed.). New Delhi: Dorling Kindersley.

Laroche, M., Papadopoulos, N., Heslop, L. A., \& Mourali, M. (2005). The influence of country image structure on consumer evaluations of foreign products. International Marketing Review, 22(1), 96-115.

Mak, V. (2008). The emergence of opinion leaders in social networks. Social Science Research Network. 
Available at: http://ssrn.com/abstract=1157285

Makgosa, R., \& Mohube, K. (2007). Peer influence on young adults' products purchase decisions. African Journal of Business Management, 1(3), 64-71.

Mangold, W., Miller, F., \& Brockway, G. (1999). Word-of-mouth communication in the service marketplace. Journal of Services Marketing, 13(1) 73 - 89.

Maxham, J., \& Netemeyer, R. (2002). A longitudinal study of complaining customers' evaluations of multiple service failures and recovery efforts. Journal of Marketing, 66(4), 57-71.

Minsner, R. (1999). The world's best known marketing secret: Building your business with word-of-mouth marketing ( $2^{\text {nd }}$ ed.). Austin: Bard Press.

Murray, K. B. (1991). A test of services marketing theory: Consumer information acquisition activities. Journal of Marketing, 55(1), 10-25.

Park, C., \& Lessig, V. (1977). Students and housewives: Differences in susceptibility to reference group influence. Journal of Consumer Research, 4(2), 102-110.

Pentina, I., Prybutok, V. R., \& Zhang, X. (2008). The role of virtual communities as shopping reference groups. Journal of Electronic Commerce Research, 9(2), 114-136.

Richins, M. (1983). Negative word-of-mouth by dissatisfied consumers: A pilot study. Journal of Marketing, 47(1), 68-78.

Spencer, L. (2003, April). Digital Marketing, A new marketing tool for businesses. Spider, 52(3), pp. 16-18.

Taylor, J. (2003, March 6). Word of mouth is where it's at. Brandweek, 44(22), pp. 26.

Tischler, L. (2004, May). What's the buzz? Boston Globe, pp. 14.

Trusov, M., Bucklin, R., \& Pauwels, K. (2009). Effects of word-of-mouth versus traditional marketing: Findings from an internet social networking site. Journal of Marketing, 73(5), 90-102.

Yoh, T. (2005). Information sources for college students athletic shoe purchasing. Smart Online Journal, $1,28-34$. 